\title{
Longwave Radiative Effect of the Cloud-Aerosol Transition Zone Based on CERES Observations
}

\author{
Babak Jahani ${ }^{1}$, Hendrik Andersen ${ }^{2,3}$, Josep Calbóo ${ }^{1}$, Josep-Abel González ${ }^{1}$, Jan Cermak ${ }^{2,3}$ \\ ${ }^{1}$ Departament de Física, Universitat de Girona, Girona, Spain \\ $5 \quad{ }^{2}$ Institute of Meteorology and Climate Research, Karlsruhe Institute of Technology (KIT), Karlsruhe, Germany \\ ${ }^{3}$ Institute of Photogrammetry and Remote Sensing, Karlsruhe Institute of Technology (KIT), Karlsruhe, Germany \\ Correspondence to: B. Jahani (babak.jahani@udg.edu)
}

\begin{abstract}
This study presents an approach for quantification of cloud-aerosol transition zone broadband longwave radiative effects at the top of the atmosphere (TOA) during daytime over the ocean, based on satellite observations and radiative

10 transfer simulation. Specifically, we used several products from MODIS (Moderate Resolution Imaging Spectroradiometer) and CERES (Clouds and the Earth's Radiant Energy System) sensors for identification and selection of CERES footprints with horizontally homogeneous transition zone and clear-sky conditions. For the selected transition zone footprints, radiative effect was calculated as the difference between the instantaneous CERES TOA upwelling broadband longwave radiance observations and corresponding clear-sky radiance simulations. The clear-sky radiances were simulated using the Santa

15 Barbara DISORT Atmospheric Radiative Transfer model fed by the hourly ERA5 reanalysis (fifth generation ECMWF reanalysis) atmospheric and surface data. The CERES radiance observations corresponding to the clear-sky footprints detected were also used for validating the simulated clear-sky radiances. We tested this approach using the radiative measurements made by the MODIS and CERES instruments onboard Aqua platform over the south-eastern Atlantic Ocean during August 2010. For the studied period and domain, transition zone radiative effect (given in flux units) is on average equal to $8.0 \pm 3.7 \mathrm{~W} \mathrm{~m}^{-2}$ (heating effect; median: $5.4 \mathrm{~W} \mathrm{~m}^{-2}$ ), although cases with radiative effects as large as $50 \mathrm{~W} \mathrm{~m}^{-2}$ were found.
\end{abstract}




\section{Introduction}

Cloud and aerosol are the particular names for two specific particle suspensions in the atmosphere, which have been widely studied but continue to contribute the largest uncertainty to estimates and interpretations of the Earth's changing energy budget (Boucher et al., 2013). One of the sources of this uncertainty is the fact that they are univocally differentiated in the atmospheric science, whereas clouds and aerosols co-exist and often interact with each other, making it hard to study the effects of one regardless of the other. For instance, aerosols in the vicinity of clouds are usually hydrated in part, and their size distribution and thus their optical characteristics change relative to their dry counterpart (Várnai \& Marshak, 2011). On the other hand, aerosols also affect cloud optical and microphysical properties through acting as cloud condensation nuclei and ice nucleating particles (Rosenfeld et al., 2014). Moreover, the decision on what a cloud is, or in other words where the boundaries of the clouds should be put, is a point of debate (Bar-Or et al., 2011; Calbó et al., 2017; Eytan et al., 2020; Fuchs \& Cermak, 2015) and a suspension detected as cloud by one method may be labeled differently by another. This is due to the presence of a phase called the transition zone (or twilight zone) between the cloudy and so-called cloud-free skies, at which the characteristics of the suspension lay between those corresponding to the adjacent clouds and the surrounding aerosol (Koren et al., 2007; Várnai et al., 2013). This phase consists of a mixture of liquid droplets and humidified to dry aerosols, and involves various processes such as cloud dissipation/formation, aerosol hydration/dehydration, shearing of cloud fragments, clouds becoming undetectable, etc. (Eytan et al., 2020; Koren et al., 2009).

Observations have shown that transition zone occurs often over large areas. According to Koren et al. (2007), at any time

40 almost $30-60 \%$ of the global atmosphere categorized as clear sky (cloud-free) can potentially contain this phase, which may expand up to 30 kilometers away from the detectable clouds (Bar-Or et al., 2011). On the basis of three ground-based observation systems, Calbó et al. (2017) quantified, at two mid-latitude sites, that the frequency of the transition zone was about 10\%. A global analysis based on MODIS (Moderate Resolution Imaging Spectroradiometer) products performed by Schwarz et al. (2017) also suggests a frequency of $20 \%$ for the occurrence of the transition zone.

45 If the area covered with the suspension of particles with the characteristics of the transition zone is so vast, the question "what role does the transition zone play in the determination of the Earth's energy budget?" takes a great importance. However, as the information available about the transition zone and its interactions with radiation (in both longwave and shortwave bands) is very limited, the area corresponding to the transition zone in climatic, meteorological, and atmospheric studies and models is usually considered as an area containing either aerosols or optically thin clouds. This means that either radiative properties of clouds or those of aerosols are used to describe the radiative properties of the transition zone. Based upon sensitivity analysis performed using radiative transfer parameterizations, two recent studies (Jahani et al. 2019, 2020) showed that this assumption may lead to substantial differences in the simulated broadband shortwave and longwave radiative effects. According to these studies, for some particular situations, at an optical depth of 0.1 (at $0.550 \mu \mathrm{m}$ ) the 
differences at surface and top of the atmosphere may be as large as 7.5 and $28 \mathrm{~W} \mathrm{~m}^{-2}$ in broadband longwave and total shortwave, respectively. Based upon an observational and statistical study, Eytan et al. (2020) estimated the top of the atmosphere (TOA) radiative effect of the transition zone around shallow warm clouds in the atmospheric window region (8.4-12.2 $\mu \mathrm{m}$ ). They found that over the oceans on average the transition zone radiative effect in the mentioned spectral region is about $0.75 \mathrm{~W} \mathrm{~m}^{-2}$ (although they found cases with average radiative effects as large as $4 \mathrm{~W} \mathrm{~m}^{-2}$ ), which is equal to the radiative forcing resulting from increasing atmospheric $\mathrm{CO}_{2}$ by $75 \mathrm{ppm}$. The overall radiative effects of the transition zone are likely to be higher, as the radiative effect estimations given in the latter study correspond to a lower bound of the effect and are limited to the low-level (warm) transition zone conditions. These results highlight the importance of the characterization of the transition zone as well as of quantifying the role it plays in the determination of Earth's energy budget.

Although the transition zone is frequently neglected in cloud-aerosol related studies, the above numbers and the vast area

65 that potentially may contain the transition zone state give importance to the necessity of further exploring it. For this reason, within the frame of the study, a method for the quantification of the broadband longwave radiative effects of the transition zone at TOA over the ocean on the basis of instantaneous satellite observations and radiative transfer calculations is presented. This method is then applied over the South-Eastern Atlantic Ocean, where cloudy conditions are frequent and hence transition zone conditions are also expected to be frequently observed.

\section{$70 \quad 2$ Methods}

\subsection{Satellite Observations}

The CERES (Clouds and the Earth's Radiant Energy System) sensor is a three-channel scanning radiometer measuring the broadband outgoing shortwave (0.3-5 $\mu \mathrm{m})$, window-region (8-12 $\mu \mathrm{m})$ and longwave (5-100 $\mu \mathrm{m})$ radiances at TOA with a spatial resolution of $\sim 20 \mathrm{~km}$ at nadir (Loeb et al., 2001; Priestley et al., 2011). The Level-2 Single Scanner Footprint (SSF)

75 product of this instrument provides information about the instantaneous outgoing broadband longwave radiances at TOA regardless of the sky condition (Loeb et al., 2018; Loeb et al., 2006). From the SSF Level-2 product, we obtained the entire daytime instantaneous TOA outgoing broadband longwave radiance observations of the CERES instrument onboard Aqua spacecraft ( $\uparrow \mathrm{L}_{\mathrm{CERES}}$ ) along with the corresponding time, geolocation, viewing geometry and surface emissivity parameters for August 2010 for the region comprised within $21^{\circ} \mathrm{W}-21^{\circ} \mathrm{E}$ and $10^{\circ} \mathrm{N}-50^{\circ} \mathrm{S}$.

80 In addition, several products from the MODIS (Moderate Resolution Imaging Spectroradiometer) instrument onboard the same satellite (Aqua) were used for identification of horizontally homogenous clear-sky and transition zone conditions within CERES footprints. Specifically, we used the ocean products: (1) geolocation (MYD03, MODIS Characterization Support Team (MCST), 2017); (2) Aerosol-Cloud-Mask and Aerosol Optical Depth (AOD) taken from the Level-2 Aerosol (MYD04, Levy et al., 2015); (3) Cloud Optical Depth (COD) from the Level-2 Cloud (MYD06, Platnick et al., 2015); and 
85 (4) Cloud Mask (MYD35, Ackerman \& Frey, 2015). These products were obtained for all MODIS-Aqua granules that contain data in the region $0^{\circ} \mathrm{E}-15^{\circ} \mathrm{E}$ and $10^{\circ} \mathrm{S}-30^{\circ} \mathrm{S}$ during August 2010, which their data spreads over the area between $21^{\circ} \mathrm{W}-21^{\circ} \mathrm{E}$ and $10^{\circ} \mathrm{N}-50^{\circ} \mathrm{S}$. By combining these products, MODIS pixels were classified into the classes "Difficult", "Cloud", “Aerosol”, "Clear", "Lost A", "Lost B", "Lost C" at 1-km resolution (at nadir) following the procedure explained in Schwarz et al. (2017). Among them, the pixels labeled as "Lost" are assumed to correspond to the transition zone conditions. Indeed, for these pixels neither aerosol nor cloud optical property retrievals exist, yet they are classified as containing a cloud (Lost A), a non-cloud obstruction (Lost B), or were not processed at all in the cloud masking (Lost C).

The processed MODIS data was then integrated from 1-km resolution to CERES native resolution to determine the fraction of each class and the average values of COD and AOD in the CERES footprints, considering equal weights for all MODIS pixels. Afterwards, only CERES footprints meeting all the following conditions were used in the analysis: (i) solar zenith angles and CERES viewing zenith angles at surface lower than $60^{\circ}$ (to mitigate the effect of uncertainties derived from viewing and solar geometries), (ii) no land MODIS pixels as determined using the MYD35 data is included, and (iii) number of ocean MODIS pixels more than or equal to $75 \%$ of the expected 400 pixels falling within CERES field of view (FOV; to exclude FOVs located on the edges of the MODIS granules). Among the remaining footprints, those with a "Lost" fraction (all lost classes together) greater than or equal to $90 \%$ were classified as horizontally homogeneous transition zone footprints (the transition zone footprints selected this way, may contain up to $10 \%$ of cloud contamination). Also, those having AOD and COD equal to zero, "Lost" fraction less than 10\%, and "Difficult" fraction less than $10 \%$ were classified as horizontally homogeneous clear-sky footprints. Based on this classification criterion, a total number of 5441 clear-sky and 3783 transition zone footprints were detected over the South-Eastern Atlantic Ocean in August 2010. The spatial distribution of these footprints is presented in Figure 1. 


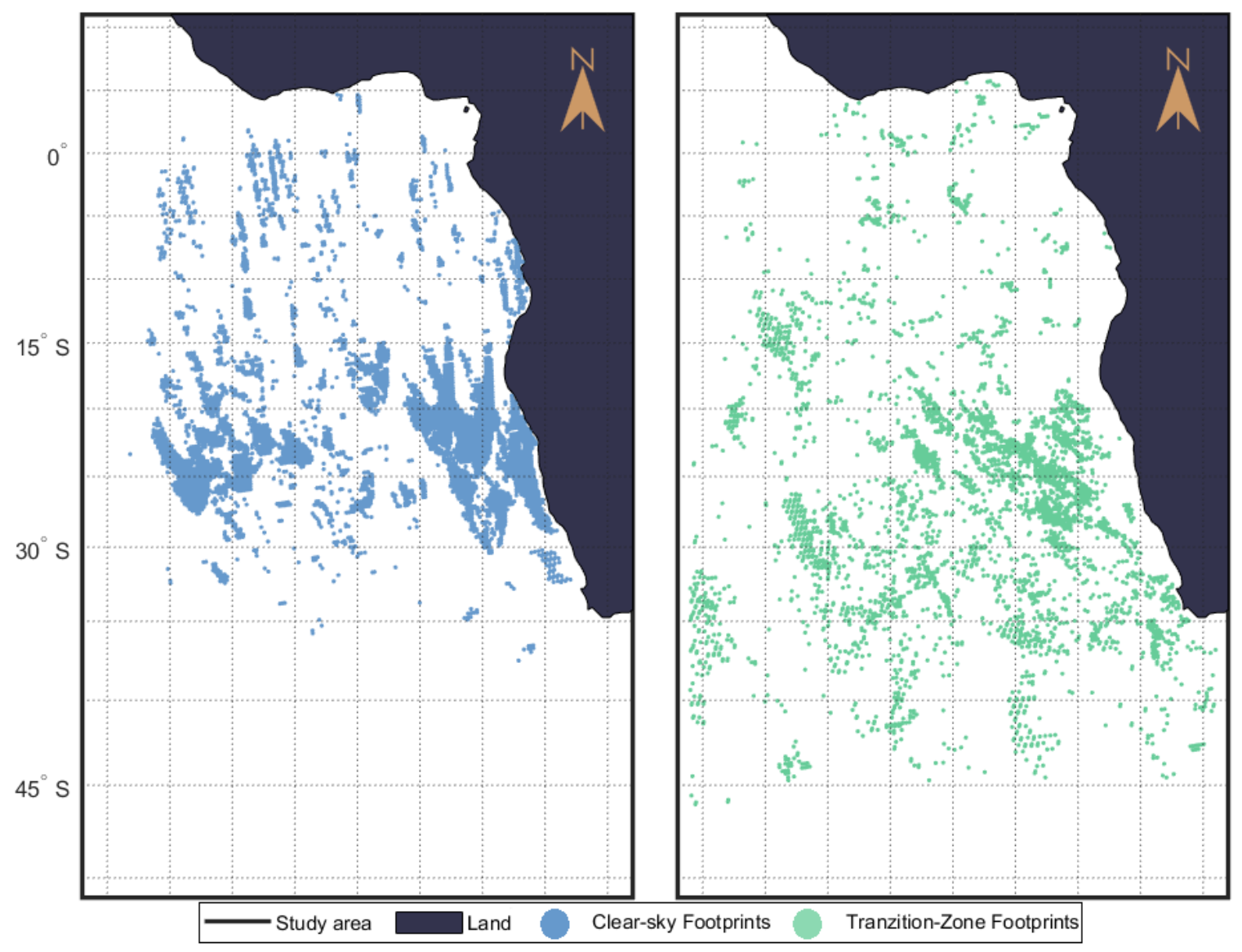

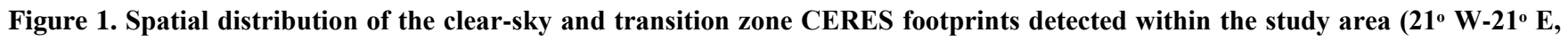
$10^{\circ} \mathrm{N}-50^{\circ} \mathrm{S}$ ) in August 2010.

\subsection{Clear-sky simulations}

For all transition zone and clear-sky footprints selected according to the criteria explained in section 2.1, the TOA upwelling broadband longwave $(5-100 \mu \mathrm{m})$ clear-sky radiances $\left(\uparrow \mathrm{L}_{\mathrm{RTM}, \mathrm{clr}}\right)$ for the CERES viewing zenith angle $(\boldsymbol{\theta})$ were simulated using the Santa Barbara DISORT Atmospheric Radiative Transfer model (SBDART, Ricchiazzi et al., 1998), considering the effect of all atmospheric gases. The simulations were carried out by using atmospheric profiles (Hersbach et al., 2018a) and surface (Hersbach et al., 2018b) values provided by the fifth generation ECMWF reanalysis (ERA5), which render the data at $0.25^{\circ} \times 0.25^{\circ}$ spatial resolution and $1 \mathrm{~h}$ time intervals. Specifically, profiles of specific humidity, geopotential height, ozone mass mixing ratio, and temperature at all available pressure levels (1000 hPa-1 hPa), as well as mean sea level pressure and $2 \mathrm{~m}$ air temperature and dewpoint temperature were used. For each (clear-sky/transition-zone) footprint, the surface and atmospheric data of the closest ERA5 cell were combined with each other and linearly interpolated in time 
according to the CERES time of observation. The combined and interpolated profiles were then fed to SBDART for simulation of $\uparrow L_{R T M, c l r}$. In these simulations, the broadband sea surface emissivity and the $\mathrm{CO}_{2}$ concentration in atmosphere were set to the constant values of 0.982 (equal to the estimated broadband longwave sea surface emissivity included in the CERES SSF data; Geier et al., 2003) and $388.71 \mathrm{ppm}$ (which is the value corresponding to the year 2010; European Environmental Agency: https://www.eea.europa.eu/, last access: 13 May 2021), respectively. As for the other gases the default concentration values included in SBDART model were used. For each individual clear-sky and transition zone footprint, SBDART model was ran with 20 zenithal streams and the spectral upwelling radiances (including the solar contribution, which actually is very low) were calculated in the range of 5-100 $\mu \mathrm{m}$ in steps of $0.2 \mu \mathrm{m}$. Then, the upwelling radiances at $30 \mathrm{~km}$ altitude at the SBDART computational zenithal angles were outputted and linearly interpolated to determine the magnitude of the upwelling radiance in the direction $\theta$. Throughout this paper, we give negative sign to the physically upwelling radiances.

The simulated clear-sky radiances $\left(\uparrow L_{R T M, \text { clr }}\right.$ ) were then validated through comparing them with the $\uparrow L_{\text {CERES }}$ values 130 corresponding to the clear-sky footprints ( $\uparrow \mathrm{L}_{\mathrm{CERES}, \mathrm{cr}}$ ). The comparison was made using the corresponding isotropic irradiances ( $\pi \uparrow L_{\text {CERES,clr }}$ and $\pi \uparrow L_{R T M, c l r}$ ), and was based on the linear correlation coefficient between the simulated and the measured values, as well as by analyzing the probability distribution, mean and variance of the differences. First, for each individual clear-sky footprint, the difference between the calculated and observed clear-sky upward irradiances $\left(\varepsilon_{\mathrm{clr}}, \mathrm{W} \mathrm{m}^{-2}\right)$ was determined according to Eq. 1:

$135 \varepsilon_{\mathrm{clr}}=\pi \uparrow \mathrm{L}_{\mathrm{RTM}, \mathrm{clr}}-\pi \uparrow \mathrm{L}_{\mathrm{CERES}, \mathrm{clr}}$ Eq. 1 Second, outliers were removed from the dataset by applying the quartiles method. Thus, among all clear-sky footprints (5441 footprints), those with a $\varepsilon_{\text {clr }}$ more than 1.5 interquartile ranges above the upper quartile or below the lower quartile (197 footprints) were discarded. Statistical analysis of the $\varepsilon_{\text {clr }}$ values corresponding to the remaining clear-sky footprints showed that $\pi \uparrow L_{\mathrm{RTM}, \mathrm{clr}}$ and $\pi \uparrow \mathrm{L}_{\mathrm{CERES}, \mathrm{clr}}$ values are strongly correlated $\left(\mathrm{r}^{2}=0.96\right)$ and that $\varepsilon_{\mathrm{clr}}$ values are normally distributed around

140 the mean value (hereafter denoted as $\bar{\varepsilon}_{\text {clr }}$ ) of about $8.0 \mathrm{~W} \mathrm{~m}^{-2}$ with a standard deviation of about $1.9 \mathrm{~W} \mathrm{~m}^{-2}$. The probability

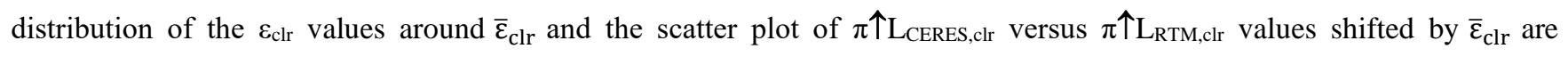
provided in Figure 2. 

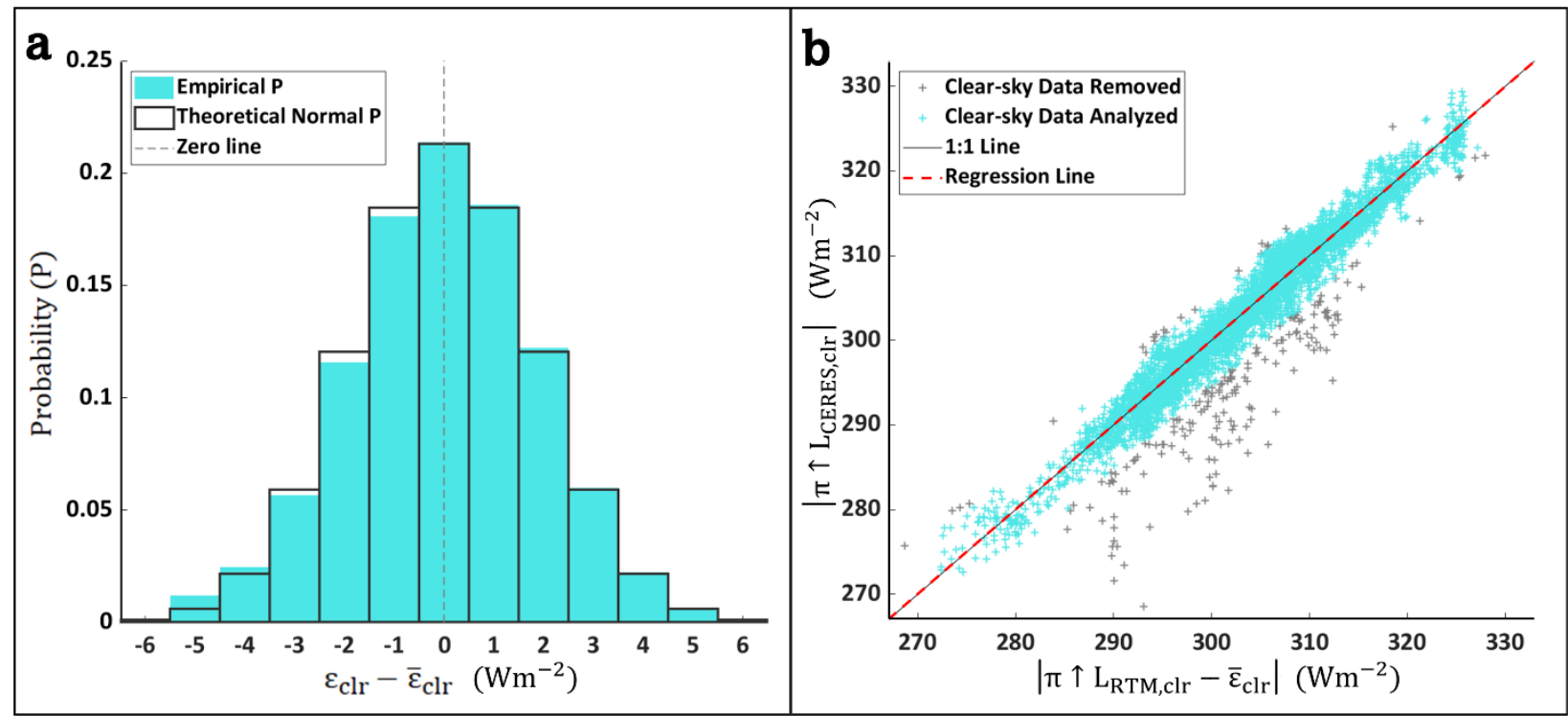

Figure 2. (a) Empirical (solid turquoise fill) and fitted theoretical normal (black lines) probability distributions of $\varepsilon_{\mathrm{clr}}$ around $\bar{\varepsilon}_{\mathrm{clr}}$, (b) scatter plots of $\pi \uparrow L_{C E R E S, c l r}$ versus $\pi \uparrow L_{R T M, c l r}$ values shifted by $\bar{\varepsilon}_{\text {clr }}$ in absolute sense. In Figure $2 b$, the gray points show the (outlier) data points discarded based on the quartile method.

The facts that $\varepsilon_{\mathrm{clr}}$ values are normally distributed around $\bar{\varepsilon}_{\mathrm{clr}}$ and that clear-sky observations and simulations are strongly correlated (and with a slope of the linear fit very close to 1 ) confirm that $\pi \uparrow L_{R T M, c l r}$ values are systematically biased by about $8.0 \mathrm{~W} \mathrm{~m}^{-2}\left(\bar{\varepsilon}_{\mathrm{clr}}\right)$ in comparison with the $\pi \uparrow \mathrm{L}_{\mathrm{CERES}, \mathrm{clr}}$ values. As the upwelling irradiances/radiances are negative by definition, the bias found indicates an underestimation of the simulation in absolute terms. Also, the distribution of $\varepsilon_{\text {clr }}$ values shows that a random disagreement of about $\pm 3.7 \mathrm{~W} \mathrm{~m}^{-2}$ at $95 \%$ confidence level (two-tailed, $\varepsilon_{\mathrm{clr}, 95}$ ) exists between the clearsky observations and simulations. The bias and the random disagreement must be due to the combined effect of the uncertainties associated with the data utilized and the assumptions made in the radiative transfer simulations (such as plane parallel atmosphere assumption, number of streams used in the calculations), the spectral resolution at which the radiative transfer calculations were performed (SBDART is based on LOWTRAN band models, and it was found by Wacker et al., (2009) that the spectrally integrated clear-sky downwelling longwave irradiances simulated by LOWTRAN models is systematically $6 \mathrm{Wm}^{-2}$ lower in comparison with line-by-line models or using the high resolution MODTRAN correlated-k bands), temporal and spatial matching of the ERA5 profiles with the CERES footprints, and the uncertainties associated with measuring the $\uparrow L_{\text {CERES }}$. According to Loeb et al. (2001), up to $0.2 \%$ of error with a standard deviation of $0.1 \%$ is associated with $\uparrow L_{\text {CERES }}$ which is indeed measured by subtracting the radiances received at the shortwave and total channels of the sensor with the appropriate spectral correction coefficients (not directly measured). Some proportion of this error could also be due to the longwave radiation scattered from the adjacent CERES footprints, which should be rather small as the magnitude of scattering by atmospheric particles for the wavelengths between 5 and $100 \mu \mathrm{m}$ is rather neglectable. We tested 
165 the sensitivity of $\varepsilon_{\mathrm{clr}}$ values to the input surface temperature, water vapor mixing ratio profile, surface emissivity parameters, as well as the number of zenithal streams used in the radiative transfer calculations. We found that, as expected, $\varepsilon_{\mathrm{clr}}$ values vary considerably with very small changes in surface temperature (increasing/decreasing surface temperature by $1 \mathrm{~K}$ will increase/reduce $\bar{\varepsilon}_{\text {clr }}$ by about $60 \%$ ), whereas the effect of other parameters is very small. Given the fact that the temperature may notably vary in the first 2 meters of the atmosphere, the possible bias and uncertainties associated with the ERA5

170 surface data utilized could possibly explain some parts of the disagreements (bias and uncertainty) observed between $\pi \uparrow L_{\text {CERES,clr }}$ and $\pi \uparrow L_{R T M, c l r}$.

\subsection{Transition Zone Radiative Effects}

The broadband longwave $(5-100 \mu \mathrm{m})$ radiative effect on flux (assuming an isotropic distribution for the radiance) for the transition zone footprints $\left(\mathrm{RE}_{\mathrm{trz}}, \mathrm{W} \mathrm{m}^{-2}\right)$ was calculated as the difference between the radiances measured by CERES

175 ( $\left.\uparrow \mathrm{L}_{\mathrm{CERES}, \text { trz }}\right)$ and the corresponding simulated clear-sky values ( $\left.\uparrow \mathrm{L}_{\mathrm{RTM}, \mathrm{clr}}\right)$ according to Eq. 2 :

$\mathrm{RE}_{\text {trz }}=\pi \uparrow \mathrm{L}_{\mathrm{CERES}, \mathrm{trz}}-\left(\pi \uparrow \mathrm{L}_{\mathrm{RTM}, \mathrm{clr}}-\bar{\varepsilon}_{\mathrm{clr}}\right)$

In this equation, $\bar{\varepsilon}_{\mathrm{clr}}$ is included for canceling the systematic bias in the estimation of $\uparrow L_{\mathrm{RTM}, \mathrm{clr}}$ (see Section 2.2). According to the uncertainty assessment described in section 2.2 , a random error of about $\pm 3.7 \mathrm{~W} \mathrm{~m}^{-2}$ (at $95 \%$ confidence level) is associated with the $\mathrm{RE}_{\mathrm{trz}}$ values calculated this way. Worth mentioning that as in the present study we have given negative

180 sign to the physically upwelling radiances, a positive and negative $\mathrm{RE}_{\text {trz }}$ will imply heating and cooling effects, respectively. Also, it should be noted that $\mathrm{RE}_{\text {trz }}$ values determined this way are indeed $\mathrm{RE}$ on radiance, despite they are presented in irradiance units $\left(\mathrm{W} \mathrm{m}^{-2}\right)$ assuming isotropic radiance. 


\section{Results and Discussion}

Figure 3 shows the probability distribution of the $\mathrm{RE}_{\mathrm{trz}}$ values obtained from analyzing the 3783 transition zone CERES footprints detected over the South-East Atlantic region during August 2010 based on the criteria and methods explained in section 2. In this figure, the left and right axis show the cumulative and absolute empirical probabilities of $\mathrm{RE}_{\mathrm{trz}}$, respectively. The box plot given in this figure also summarizes the $\mathrm{RE}_{\mathrm{trz}}$ values calculated for all transition zone footprints. The bar chart shows the mean frequency of the three MODIS lost classes (A, B and C) in the CERES transition zone footprints analyzed. From this figure it can be seen that "Lost A" is the most frequent class among all the "Lost" classes, followed by "Lost B" and "Lost C", which is in line with the results of Schwarz et al. (2017). The absolute probability of the $\mathrm{RE}_{\mathrm{trz}}$ values provided in Figure 3 shows that for the studied period and domain the $\mathrm{RE}_{\mathrm{trz}}$ values extend from -4 to $50 \mathrm{~W} \mathrm{~m}^{-2}$ and follow a right-skewed distribution with a mean and median of about 8.0 and $5.4 \mathrm{~W} \mathrm{~m}^{-2}$, respectively. Among these values, a vast majority (84\%) of them are positive. This implies that, as expected, for the vast majority of the transition zone CERES footprints analyzed, the outgoing longwave radiation at TOA was smaller than what it would have been if no suspension was present (as in the present study the upwelling radiances have been indicated with negative signs). In other words, the results show that at most of these footprints, a suspension of particles exists which cannot be classified as cloud or aerosol, but it is clearly interacting with the longwave radiation emitted from the sea surface and causing a reduction in the outgoing longwave radiation at TOA (heating effect). The information provided in Figure 3 also shows that for around 60\% of the cases analyzed, the magnitude of the interactions of this suspension is indeed greater than that of the uncertainties associated with the methodology adopted $\left( \pm 3.7 \mathrm{~W} \mathrm{~m}^{-2}\right)$. These facts prove that the radiative effects shown in Figure 3 are not coincidental; contrarily, they must be due to the transition zone particle suspension. They also prove that the transition zone occurs over a vast area which makes it possible to observe its TOA radiative signature in radiative measurements at a spatial resolution as coarse as that of CERES. The heating effects corresponding to the transition zone footprints with the magnitude of $\mathrm{RE}_{\mathrm{trz}}$ greater than that of the method uncertainty must be due to the absorption of the longwave radiation emitted from the

205 sea surface by the transition zone particles and the subsequent emission by the same particles at a temperature which is considerably cooler than that of the sea surface. 


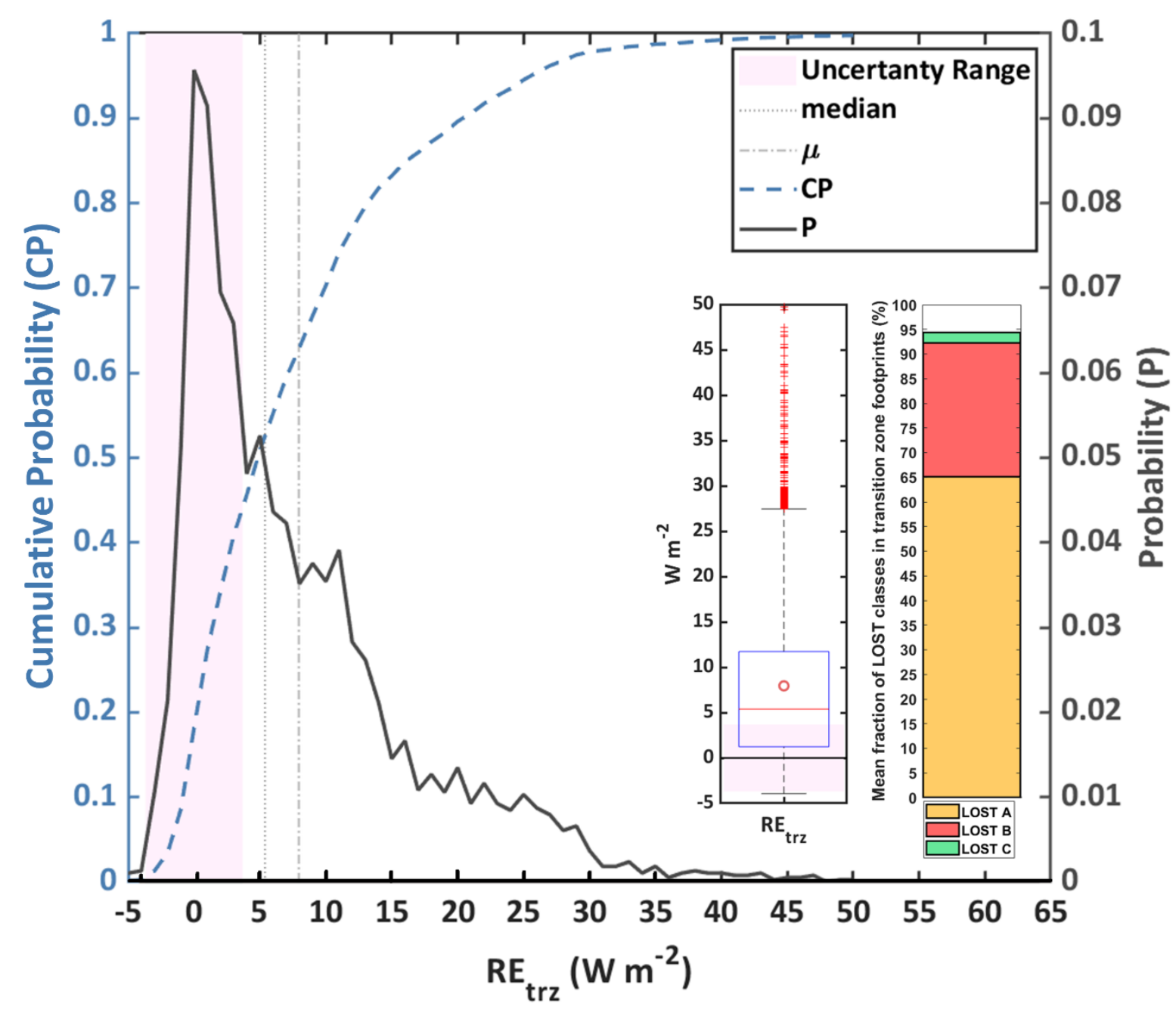

Figure 3. Empirical cumulative (left axis) and absolute (right axis) probability distributions of the $\mathrm{RE}_{\text {trz }}$ calculated for the 3783 transition zone footprints selected in the South-East Atlantic Ocean during August 2010. In this figure, the $\mathbf{R E}_{\text {trz }}$ bins are $1 \mathrm{~W}^{-2}$ wide and centered at each enter number. The area colored in pink shows the uncertainty range, which was obtained through

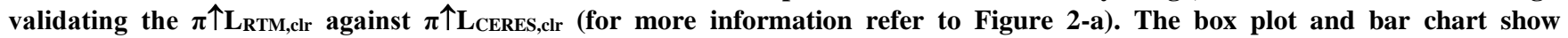
dispersion of the $\mathrm{RE}_{\mathrm{trz}}$ values and mean fraction of the "Lost" classes in the transition zone footprints analyzed, respectively. (note: in this figure, $\mu$ stands for mean of $\mathrm{RE}_{\text {trz }}$ )

The fact that the probability distribution of the $\mathrm{RE}_{\mathrm{trz}}$ values is right-skewed and has a tail extending up to $50 \mathrm{~W} \mathrm{~m}^{-2}$, also indicates that the REs calculated in the present study are due to particle suspensions between cloud-free and cloudy skies with different micro- and macro-physical characteristics, which is to be expected and is consistent with what is referred to as the transition zone: a phase of particles between the cloudy and so-called cloud-free skies, at which the characteristics of the suspension lay between those corresponding to the adjacent clouds and the surrounding aerosols (Koren et al., 2007; Várnai et al., 2013). Among all $\mathrm{RE}_{\mathrm{trz}}$ values illustrated in Figure 3, for example, almost $41 \%$ of them are within the uncertainty range $\left(-3.7 \leq \mathrm{RE}_{\mathrm{trz}} \leq 3.7 \mathrm{~W} \mathrm{~m}^{-2}\right)$. These $\mathrm{REs}$, which comprise almost all $(98 \%)$ negative and $30 \%$ of the positive $\mathrm{RE}_{\mathrm{trz}}$ values, 
could potentially represent transition zone conditions with characteristics very close to clear-sky condition (relatively low concentration of particles), or those at which the upward emission by transition zone suspension is performed at temperatures close to the sea surface temperature. Whereas the extreme values at the right tail of the distribution $\left(\mathrm{RE}_{\mathrm{trz}}\right.$ values greater than $27.6 \mathrm{~W} \mathrm{~m}^{-2}$, shown with red marks in the boxplot given in Figure 3, that is the $3.7 \%$ highest values) correspond to transition zone footprints which are contaminated with the edges of optically thick clouds, as the transition zone footprint selection criteria applied in the present study allows up to $10 \%$ contribution from other classes (see section 2.1).

The difference between the temperatures at which the emission is performed (dT, K), specifically between the sea surface and the top of a parcel of an atmospheric particle suspension, plays a primary role in the longwave RE of this suspension at TOA. It also provides some descriptive information about the characteristics of the particle suspension. To be able to further characterize the transition zone conditions detected within the study area, dT was approximated for each transition zone footprint. In this approximation sea surface temperature was taken equal to the ERA5 reanalysis $2 \mathrm{~m}$ air temperature corresponding to the closest ERA5 grid cell linearly interpolated in time according to the time of observation (i.e., the temperature used in the clear-sky simulations). Transition zone suspension top temperature was assumed equal to CERES SSF levels 2 instantaneous cloud top temperature (Minnis et al., 2011). This assumption was made because this parameter is indeed the average of MODIS cloud top temperature retrievals made for the cloudy MODIS pixels (determined by the MODIS cloud mask) falling within CERES FOV. It should be noted that in case of the transition zone footprints, according to the bar chart provided in Figure 3,65\% of the MODIS pixels were labeled as "Lost A", and that for "Lost A" pixels, cloud top temperature was retrieved, as they were initially labeled as cloud by the cloud mask. In other words, for the transition zone footprints, the temperature of the top of the suspension is the result of averaging cloud top temperature retrieved for both the "Lost A" pixels and the potential cloudy pixels falling within the remaining $\leq 10 \%$ of the FOV (see section 2.1 for more information).

Figure 4 shows the values of $\mathrm{RE}_{\mathrm{trz}}$ as a function of dT. In this figure, gray filled circular markers, yellow crosses and vertical blue lines show the mean and median and standard deviation of the $\mathrm{RE}_{\mathrm{trz}}$ values corresponding to each dT bin, respectively. The horizontal black lines also indicate the width of each dT bin. The information provided in this figure shows that $\mathrm{RE}_{\text {trz }}$ is strongly correlated with $\mathrm{dT}$ and it increases with $\mathrm{dT}$, which confirms the abovementioned statement regarding the relationship between RE and temperature at which the LW radiation is emitted. From this figure it can also be seen that dT for the transition zone footprints analyzed in the present study varies between -1.5 and $31 \mathrm{~K}$. This implies that the transition zone footprints selected and analyzed in the present study in fact represent transition zone conditions at different altitudes (i.e., dT increases with altitude) and with different characteristics. The transition zone footprints with relatively small dT values (specifically those falling in the first four dT bins shown in Figure 4), for example, could potentially represent transition zone conditions near the sea surface with characteristics similar to those of the low clouds. According to Figure 4, $\mathrm{RE}_{\mathrm{trz}}$ corresponding to these latter footprints, which comprise around $85 \%$ of the footprints that their $\mathrm{RE}_{\mathrm{trz}}$ falls within the uncertainty range (see Figure 3), is on average about $0.8 \mathrm{~W} \mathrm{~m}^{-2}$. This number is closely in agreement with what was found by Eytan et al. (2020) as the globally averaged magnitude of $\mathrm{RE}_{\mathrm{trz}}$ around the warm low cloud fields $\left(\sim 0.75 \mathrm{~W} \mathrm{~m}^{-2}\right)$, even 
255 though the method adopted by them is quite different to what is proposed in the present study. Specifically, in Eytan et al. (2020) distance from the nearest cloud (Koren et al., 2007) was used as a statistical measure for the likelihood of finding twilight conditions and $\mathrm{RE}_{\mathrm{trz}}$ was calculated based on mean TOA MODIS radiance observations. In contrast, the methodology proposed in the present study is based on instantaneous satellite observations and radiative transfer calculations. Furthermore, the fact that the dT corresponding to the present study transition zone footprints varies between 1.5 and $31 \mathrm{~K}$ shows that the methodology proposed in the present study is capable of capturing the radiative signatures of transition zone conditions with a broad range of characteristics at CERES measurement spatial resolution and thus can be applied for studying REs of transition zone conditions with different characteristics.

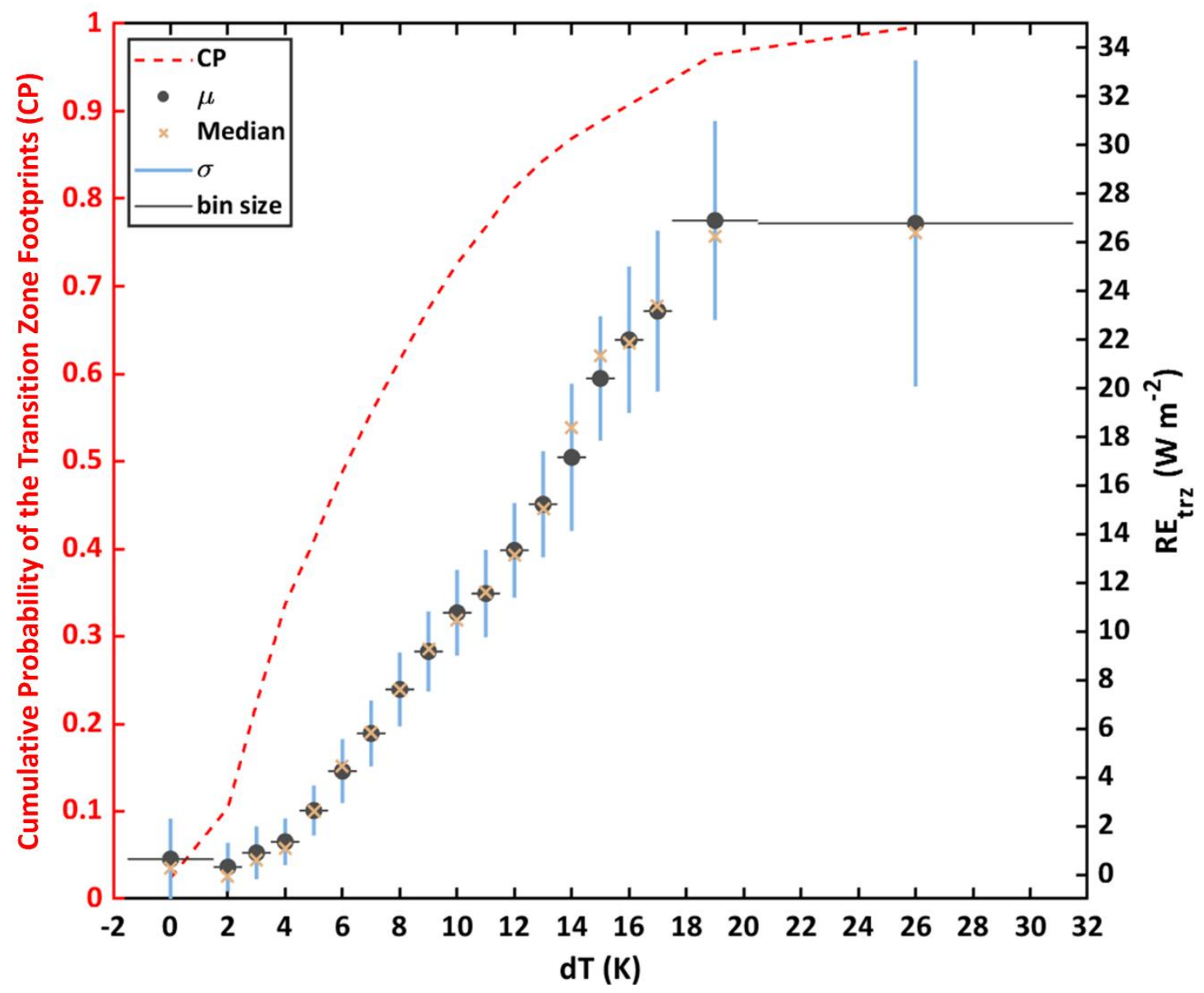

Figure 4. Cumulative probability (left axis) and $R_{\text {trz }}$ (right) of the transition zone footprints analyzed as a function of dT. The vertical blue lines, black circles and yellow crosses indicate the standard deviation $(\sigma)$, mean $(\mu)$ and median of the REtrz values in each dT bin, respectively. The horizontal black lines show the width of each dT bin. The $\mathbf{r}^{2}$ values given in this figure show the determination coefficients between mean (and median) values of $\mathrm{RE}_{\mathrm{trz}}$ corresponding to the $\mathrm{dT}$ bins and $\mathrm{dT}$. 


\section{Summary, Conclusions, and implications for atmospheric research}

In the present study, a method for quantification of the broadband longwave radiative effects of the transition zone at TOA $\left(\mathrm{RE}_{\mathrm{trz}}\right)$ during daytime over the ocean based on satellite observations and radiative transfer simulations was proposed. Specifically, $\mathrm{RE}_{\mathrm{trz}}$ was computed as the difference between the longwave irradiance as measured by CERES (Clouds and the Earth's Radiant Energy System) and the clear-sky irradiance as computed by Santa Barbara DISORT Atmospheric Radiative Transfer (SBDART) model run for the same place and moment, with the input data from ERA5 reanalysis. The identification of the transition zone conditions (CERES footprints) is based on MODIS (Moderate Resolution Imaging Spectroradiometer) products following the Schwarz et al. (2017) method, and 3783 cases have been found for the analyzed area in the SE Atlantic Ocean for August 2010. The uncertainty of the method for RE estimation was assessed by means of applying the same approach on clear-sky regions. This approach was applied to the data recorded by the CERES and MODIS sensors onboard Aqua platform during August 2010 over the South-East Atlantic Ocean. The results obtained from this analysis can be summarized as follows:

- The transition zone occurs over vast areas which makes it possible to observe its TOA radiative signature in radiative measurements at a spatial resolution as coarse as that of CERES.

- The methodology proposed in the present study is capable of quantifying the radiative effects of transition conditions with a wide range of characteristics with an accuracy of about $\pm 3.7 \mathrm{~W} \mathrm{~m}^{-2}$ at $95 \%$ confidence level, based on instantaneous satellite measurements and radiative transfer simulations.

- For the studied period and domain, $\mathrm{RE}_{\mathrm{trz}}$ is on average equal to $8.0 \mathrm{~W} \mathrm{~m}^{-2}$ (heating effect; median: $5.4 \mathrm{~W} \mathrm{~m}^{-2}$ ), although cases with $\mathrm{RE}_{\mathrm{trz}}$ with magnitudes as large as $50 \mathrm{~W} \mathrm{~m}^{-2}$ were observed.

- Low-level transition zone conditions (determined based on the difference between the layer top and surface temperature) on average produce a RE of about $0.8 \mathrm{~W} \mathrm{~m}^{-2}$.

These results and those found by other studies show that the transition zone is indeed an important phase of particle suspensions in the atmosphere with a notable radiative signature in the longwave region, which deserves to be further investigated. The methodology presented in the current study provides the opportunity to gather information about the longwave radiative effects of homogeneous transition zone conditions with different characteristics. This information can be useful for characterizing the transition zone as an additional intermediate phase of particle suspension (class) between cloudy and cloud-free skies (containing aerosols or not) in the remote sensing algorithms, as well as in climatic, meteorological, and atmospheric studies. Nevertheless, this approach only provides information about the longwave radiative effects of the transition zone and the $\mathrm{RE}_{\mathrm{trz}}$ values given in the present study were obtained by analyzing only one month of data at a particular study area. To be able to understand the role that the transition zone plays in the determination of the Earth's energy budget and the climate system, it is required to study the transition zone radiative effects in both longwave and shortwave spectral bands over larger domains and longer time spans. These aspects should be the matter of future research efforts. 


\section{Code availability}

The source codes of Santa Barbra DISORT Atmospheric Radiative Transfer (SBDART) model can be accessed from https://github.com/paulricchiazzi/SBDART.git, last access: May 2021.

\section{Data Availability Statement}

305 All the data used in this study are publicly available and details on the datasets is provided in Section 2. The ERA5 reanalysis data used in this study are accessible from the Copernicus Climate Data Store at https://cds.climate.copernicus.eu/cdsapp\#!/dataset/reanalysis-era5-pressure-levels?tab=overview $\quad$ and https://cds.climate.copernicus.eu/cdsapp\#!/dataset/reanalysis-era5-single-levels?tab=overview, last access: February 2021. The MODIS data was obtained from the Level-1 and Atmosphere Archive

310 \& Distribution System (LAADS) Distributed Active Archive Center (DAAC) at https://ladsweb.modaps.eosdis.nasa.gov/, last access: February 2021. The CERES data was obtained from https://ceres-tool.larc.nasa.gov/ordtool/products?CERESProducts=SSFlevel2_Ed4, last access: February 2021.

\section{Author contribution}

All authors contributed to the development of the initial idea, design of the study, interpretation of the results and reviewing

315 the paper. Hendrik Andersen processed the MODIS data. Babak Jahani performed the computations, analyzed the data, and wrote the paper.

\section{Competing interests}

The authors declare that they have no conflict of interest.

\section{Acknowledgement}

320 This study is funded by the Spanish Ministry of Science and Innovation (project NUBESOL-2, PID2019-105901RB-I00) and Babak Jahani holds a FI-AGAUR PhD grant (2018FI_B_00830) provided by the Government of Catalonia (Universities and Research Secretariat) and the European Union. 


\section{References}

Ackerman, S. A., \& Frey, R. (2015). MODIS Atmosphere L2 Cloud Mask Product (35_L2). NASA MODIS Adaptive Processing System, Goddard Space Flight Center. https://doi.org/http://dx.doi.org/10.5067/MODIS/MYD35_L2.006

Bar-Or, R. Z., Altaratz, O., \& Koren, I. (2011). Global analysis of cloud field coverage and radiative properties, using morphological methods and MODIS observations. Atmospheric Chemistry and Physics, 11(1), 191-200. https://doi.org/10.5194/acp-11-191-2011

Boucher, O., Randall, D., Artaxo, P., Bretherton, C., Feingold, G., Forster, P., et al. (2013). Clouds and aerosols. Climate Change 2013 the Physical Science Basis: Working Group I Contribution to the Fifth Assessment Report of the Intergovernmental Panel on Climate Change, 9781107057, 571-658. https://doi.org/10.1017/CBO9781107415324.016

Calbó, J., Long, C. N., González, J. A., Augustine, J., \& McComiskey, A. (2017). The thin border between cloud and aerosol: Sensitivity of several ground based observation techniques. Atmospheric Research, 196(May), 248-260. https://doi.org/10.1016/j.atmosres.2017.06.010

Eytan, E., Koren, I., Altaratz, O., Kostinski, A. B., \& Ronen, A. (2020). Longwave radiative effect of the cloud twilight zone. Nature Geoscience, 13(10), 669-673. https://doi.org/10.1038/s41561-020-0636-8

Fuchs, J., \& Cermak, J. (2015). Where Aerosols become clouds-potential for global analysis based on CALIPSO data.

340 Remote Sensing, 7(4), 4178-4190. https://doi.org/10.3390/rs70404178

Geier, E. B., Green, R. N., Kratz, D. P., Minnis, P., Miller, W. F., Nolan, S. K., \& Franklin, C. B. (2003). CERES data management system: Single Satellite Footprint TOA/surface fluxes and clouds (SSF) collection document, release 2, version 1. Cent., Hampton, Va, Radiat. and Aerosol Branch, Atmos. Sci. Res., NASA Langley Res. Cent., Hampton, Va, available at: http://asd-www.larc.nasa.gov/ceres/collect_guide/SSF_CG.pdf.

345 Hersbach, H., Bell, B., Berrisford, P., Biavati, G., Horányi, A., Muñoz Sabater, J., et al. (2018a). ERA5 hourly data on pressure levels from 1979 to present. https://doi.org/10.24381/cds.bd0915c6

Hersbach, H., Bell, B., Berrisford, P., Biavati, G., Horányi, A., Muñoz Sabater, J., et al. (2018b). ERA5 hourly data on single levels from 1979 to present. https://doi.org/10.24381/cds.adbb2d47

Jahani, B., Calbó, J., \& González, J. A. (2019). Transition Zone Radiative Effects in Shortwave Radiation Parameterizations:

350 Case of Weather Research and Forecasting Model. Journal of Geophysical Research: Atmospheres, 124(23), $13091-13104$. https://doi.org/10.1029/2019JD031064

Jahani, B., Calbó, J., \& González, J.-A. (2020). Quantifying Transition Zone Radiative Effects in Longwave Radiation Parameterizations. Geophysical Research Letters, 47(22), https://doi.org/https://doi.org/10.1029/2020GL090408

355 Koren, I., Remer, L. A., Kaufman, Y. J., Rudich, Y., \& Martins, J. V. (2007). On the twilight zone between clouds and aerosols. Geophysical Research Letters, 34(8), 1-5. https://doi.org/10.1029/2007GL029253 
Koren, I., Feingold, G., Jiang, H., \& Altaratz, O. (2009). Aerosol effects on the inter-cloud region of a small cumulus cloud field. Geophysical Research Letters, 36(14), 1-5. https://doi.org/10.1029/2009GL037424

Levy, R., Hsu, C., Sayer, A., Mattoo, S., \& Lee, J. (2015). MODIS Atmosphere L2 Aerosol Product. NASA MODIS Adaptive

Processing System, Goddard Space Flight Center.

Loeb, N. G., Priestley, K. J., Kratz, D. P., Geier, E. B., Green, R. N., Wielicki, B. A., et al. (2001). Determination of unfiltered radiances from the clouds and the earth's radiant energy system instrument. Journal of Applied Meteorology, 40(4), 822-835. https://doi.org/10.1175/1520-0450(2001)040<0822:DOURFT>2.0.CO;2

Loeb, N. G., Su, W., Doelling, D. R., Wong, T., Minnis, P., Thomas, S., \& Miller, W. F. (2018). 5.03 - Earth's top-ofatmosphere radiation budget. In Comprehensive Remote Sensing (Vol. 5, pp. 67-84). https://doi.org/https://doi.org/10.1016/B978-0-12-409548-9.10367-7

Loeb, Norman G., Sun, W., Miller, W. F., Loukachine, K., \& Davies, R. (2006). Fusion of CERES, MISR, and MODIS measurements for top-of atmosphere radiative flux validation. Journal of Geophysical Research Atmospheres, 111(18), 111. https://doi.org/10.1029/2006JD007146

370 Minnis, P., Sun-Mack, S., Chen, Y., Khaiyer, M. M., Yi, Y., Ayers, J. K., et al. (2011). CERES edition-2 cloud property retrievals using TRMM VIRS and Terra and Aqua MODIS data-Part II: Examples of average results and comparisons with other data. IEEE Transactions on Geoscience and Remote Sensing, 49(11 PART 2), 4401-4430. https://doi.org/10.1109/TGRS.2011.2144602

MODIS Characterization Support Team (MCST). (2017). MODIS Geolocation Fields Product. NASA MODIS Adaptive

375 Processing System, Goddard Space Flight Center, USA. https://doi.org/http://dx.doi.org/10.5067/MODIS/MYD03.061

Platnick, S., Ackerman, A. S., King, M. D., Meyer, K., W.P., M., Holz, R. E., et al. (2015). MODIS atmosphere L2 cloud product (06_L2). NASA MODIS Adaptive Processing System.

Priestley, K. J., Smith, G. L., Thomas, S., Cooper, D., Lee, R. B., Walikainen, D., et al. (2011). Radiometric performance of the CERES earth radiation budget climate record sensors on the EOS Aqua and Terra spacecraft through April 2007. Journal of Atmospheric and Oceanic Technology, 28(1), 3-21. https://doi.org/10.1175/2010JTECHA1521.1

Ricchiazzi, P., Yang, S., Gautier, C., \& Sowle, D. (1998). SBDART: A Research and Teaching Software Tool for PlaneParallel Radiative Transfer in the Earth's Atmosphere. Bulletin of the American Meteorological Society, 79(10), 2101-2114. https://doi.org/10.1175/1520-0477(1998)079<2101:SARATS>2.0.CO;2

Rosenfeld, D., Andreae, M. O., Asmi, A., Chin, M., Leeuw, G. de, Donovan, D. P., et al. (2014). Global observations of aerosol-cloud-precipitation- climate interactions. Reviews of Geophysics REVIEW, 52, 750-808. https://doi.org/10.1002/2013RG000441

Schwarz, K., Cermak, J., Fuchs, J., \& Andersen, H. (2017). Mapping the twilight zone-What we are missing between clouds and aerosols. Remote Sensing, 9(6), 1-10. https://doi.org/10.3390/rs9060577

Várnai, T., Marshak, A., \& Yang, W. (2013). Multi-satellite aerosol observations in the vicinity of clouds. Atmospheric 
https://doi.org/10.5194/acp-2021-421

Preprint. Discussion started: 7 June 2021

(c) Author(s) 2021. CC BY 4.0 License.

(c) (1)

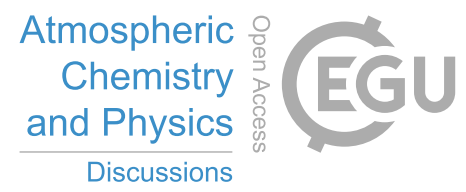

Várnai, T., \& Marshak, A. (2011). Global CALIPSO observations of aerosol changes near clouds. IEEE Geoscience and Remote Sensing Letters, 8(1), 19-23. https://doi.org/10.1109/LGRS.2010.2049982

Wacker, S., Gröbner, J., Emde, C., Vuilleumier, L., Mayer, B., \& Rozanov, E. (2009). Comparison of Measured and Modeled Nocturnal Clear Sky Longwave Downward Radiation at Payerne, Switzerland. AIP Conference Proceedings, 395 1100(1), 589-592. https://doi.org/10.1063/1.3117055 